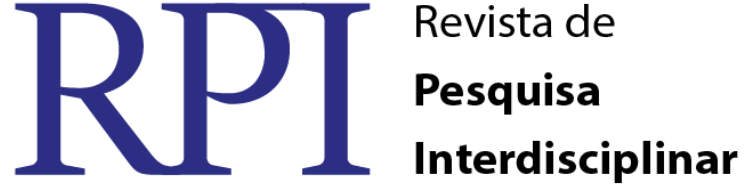

\section{INTEGRANDO SAÚDE E EDUCAÇÃO: A CONTRIBUIÇÃO DA PEDAGOGIA NUM CENTRO DE NEURORREABILITAÇÃO EM FORTALEZA/CE}

\author{
Gerlaine Belchior ${ }^{1}$ - UFCG \\ Patrícia Lima ${ }^{2}$ - Faculdades Integradas de Patos
}

\begin{abstract}
RESUMO
Este artigo traz para o âmbito acadêmico a discussão acerca da interlocução entre a área da saúde e a educação. Constitui-se no registro e análise do trabalho desenvolvido por duas pedagogas no âmbito hospitalar. Os dados foram coletados através da observação direta a partir de uma visita técnica realizada num Centro de Neurorreabilitação, no período de 01 a 05 de setembro de 2014, em Fortaleza-CE. Durante 05 dias consecutivos acompanhou-se o trabalho de duas pedagogas no âmbito hospitalar. Esta visita técnica teve por objetivo conhecer a contribuição do pedagogo na equipe multidisciplinar em um Centro de Neurorreabilitação. Metodologia. Constou de três etapas, a saber: levantamento bibliográfico, visita técnica e sistematização do trabalho escrito. Resultados: O estudo realizado confirma que a prática educativa exercida pelo pedagogo não se restringe aos muros da escola, vai além deste contexto formal. Foi possível constatar que o pedagogo que atua no âmbito hospitalar, sem dúvida tem uma função relevante no processo de reabilitação dos pacientes que são atendidos pela Unidade Hospitalar que foi locus deste estudo. Ficou evidente que esse novo espaço de atuação, exige do pedagogo qualificação, dedicação, sensibilidade, flexibilidade, competência e ética profissional. Na visita técnica realizada na Unidade Hospitalar de Fortaleza-CE constatamos que a formação acadêmica que o pedagogo recebe na universidade, nas disciplinas ofertadas pelo curso de Pedagogia, constitui uma base sólida de conhecimentos teóricos e práticos que o prepara para atuar em múltiplos contextos sociais, incluindo o hospital.
\end{abstract}

Palavras-chave: Pedagogo. Reabilitação. Interdisciplinaridade.

\section{INTEGRATING HEALTH AND EDUCATION: THE CONTRIBUTION OF PEDAGOGY IN A NEURORABILITATION CENTER IN FORTALEZA / CE}

\begin{abstract}
This article brings to the academic scope the discussion about the interlocution between the health area and education. It is the record and analysis of the work developed by two pedagogues in the hospital. Data were collected through direct observation from a technical visit performed at a Neurorehabilitation Center, from September 01 to 05, 2014, in Fortaleza-CE. During 05 consecutive days the work of two pedagogues in the hospital scope was followed. This technical visit had as objective to know the contribution of the pedagogue in the multidisciplinary team in a Center of Neuroreabilitation. Methodology. It consisted of three stages, namely: bibliographical survey, technical visit and systematization of written work. Results: The study confirms that the educational

\footnotetext{
${ }^{1}$ Maria Gerlaine Belchior Amaral. Doutorado em Educação. Professora da Universidade Federal de Campina Grande. Email: gerlaine.ufcg@yahoo.com.br

${ }^{2}$ Patrícia da Silva Lima. Especializanda em Neuropsicopedagogia. email: pathysilvalima@hotmail.com
} 
practice practiced by the pedagogue is not restricted to the walls of the school, goes beyond this formal context. It was possible to verify that the pedagogue who works in the hospital scope, undoubtedly has a relevant role in the process of rehabilitation of the patients that are attended by the Hospital Unit that was the locus of this study. It became evident that this new area of action requires the pedagogical qualification, dedication, sensitivity, flexibility, competence and professional ethics. In the technical visit carried out at the Hospital Unit of Fortaleza-CE, we find that the academic formation that the pedagogue receives at the university, in the courses offered by the Pedagogy course, constitutes a solid base of theoretical and practical knowledge that prepares him to act in multiple social contexts, Including the hospital.

Keywords: Pedagogist. Rehabilitation. Interdisciplinarity.

\section{INTRODUÇÃO}

Este artigo é o registro da análise do trabalho desenvolvido por duas pedagogas no âmbito hospitalar. Os dados foram coletados através da observação direta a partir de uma visita técnica realizada num Centro de Neurorreabilitação, no período de 01 a 05 de setembro de 2014. Durante 05 dias consecutivos acompanhou-se o trabalho de duas pedagogas no âmbito hospitalar. Esta visita técnica teve por objetivo conhecer a contribuição do pedagogo na equipe multidisciplinar em um Centro de Neurorreabilitação.

$\mathrm{Na}$ contemporaneidade o campo de atuação do pedagogo não se restringe apenas aos espaços escolares, devido a demanda socioeducativas que se intensifica a cada dia em diversos cenários sociais. De acordo CNE/CP N5, de 13 de dezembro de 2005 "A formação oferecida abrangerá, integradamente à docência, a participação da gestão e avaliação de sistemas e instituições de ensino geral, a elaboração, a execução, o acompanhamento de programas e as atividades educativas."

Além de atuar na docência, é possível encontrar este profissional atuando na Pedagogia Empresarial, Hospitalar, Social e Ambiental, além de outros espaços, tais como: ONGs, TV, rádio, presídio, editoras de revista, criação/elaboração/avaliação de brinquedos pedagógicos, etc. Libâneo (2007, p.51) assevera que "o campo de atuação do profissional formado em Pedagogia é tão vasto quanto são as práticas educativas na sociedade. Em todo lugar onde houver uma prática educativa com caráter de intencionalidade, há aí uma Pedagogia."

O Centro de Neurorreabilitação onde ocorreu o estudo desenvolve diversos Programas, tais como: Reabilitação infantil, Reabilitação lesão medular, Reabilitação neurologista, Pediatria, Reabilitação infantil/adulto. Esses Programas são efetivados por 
diversos profissionais, dentre eles o pedagogo. Consiste numa práxis interdisciplinar, que propicia um atendimento o qual concebe o sujeito como um todo e não apenas olha para a sua patologia. São considerados no sujeito: o físico, o psicológico, o social, o afetivo, e também, a família. Essa percepção do sujeito, o empenho e a competência expressos no trabalho de cada profissional propicia um atendimento de excelência.

\section{A prática educativa do pedagogo no Centro de Neurorreabilitação}

No primeiro diálogo com as pedagogas fomos informadas de que o atendimento muitas vezes acontece junto com outros profissionais, a saber: médico, enfermeiro, psicólogo, fisioterapeuta, educador físico, nutricionista, etc., ressaltam que sempre buscam fazer esses atendimentos de modo interdisciplinar, em equipe. Afirmam que a interrelação ocorre constantemente no decorrer dos atendimentos. Integração esta, a qual tivemos a oportunidade de presenciar em diversos momentos durante a visita técnica. E que enfatizamos como algo muito positivo. Foi possível ver na prática as diferentes ciências agindo em consonância a favor da vida, neste caso, promovendo a reabilitação.

O papel do pedagogo consiste em ações coletivas integradas a outros profissionais com o propósito de favorecer aos pacientes condições de qualidade de vida, desenvolvendo seus potenciais, apesar de sua limitação. Na Unidade Hospitalar onde ocorreu o estudo o pedagogo desenvolve um trabalho ligado de forma direta ao processo de reabilitação dos pacientes. Sobre a Pedagogia hospitalar Matos (2008,p.81) assinala que

A Pedagogia Hospitalar requer, pela sua especificidade, habilidades e competentes profissionais. Lança, com isto, um verdadeiro desafio aos cursos de Pedagogia a fundamentarem suas propostas curriculares a partir de bem sucedidas pesquisas e práticas científicas multi/inter/transdisciplinares em contextos hospitalares que já estão acontecendo em cenário nacional, tanto por parte de muitas instituições de ensino como em realidade hospitalares ou correlatas.

O hospital trabalha com um programa de internação que varia de duas semanas a um mês no hospital, então o trabalho desenvolvido pelas pedagogas, além do trabalho de avaliação, também é de apoio e acompanhamento à vida escolar da criança. Esse apoio não se restringe apenas ao período de internação. As pedagogas dizem que às vezes a família traz o 
material escolar para o hospital e quando isso não acontece, solicitam que tragam o material para dar subsídios para que possam planejar e organiza uma rotina de estudos. Relatam que tem muitas crianças/jovens com atraso cognitivo no desenvolvimento, então antes, de qualquer procedimento didático avaliam como essa criança está na escola - se os conteúdos estão adequados - e a partir desse levantamento fazem o planejamento. Muitas crianças precisam de adaptações para se manterem na escola, então, as pedagogas fazem um trabalho de sensibilização com a equipe escolar no processo de inclusão, trabalhando as diferenças. Elas relatam que é um trabalho desafiador o processo de inclusão na escola. É interessante destacar que o trabalho das pedagogas ocorre no hospital e estende-se até a escola. Este trabalho é relevante e inovador, pois as pedagogas orientam a escola para receberem essas crianças/jovens que passam pelo processo de reabilitação.

Desenvolvem também um trabalho chamado de Comunicação Alternativa. É todo trabalho utilizado para buscar diferentes formas de comunicação, desde uma prancha com figuras, até mesmo o uso do computador. O objetivo é a comunicação, esse atendimento é interdisciplinar realizado junto com a terapia funcional. Quando o paciente tem atraso cognitivo trabalham com a psicóloga e fonoaudióloga que auxiliam para o retorno escolar (estudantes) por meio da estimulação cognitiva e orientação profissional (pessoas adultas), estas são as principais linhas de atuação. O que se verificou a todo instante é que o trabalho do pedagogo não ocorre de forma isolada, foi possível comprovar a efetivação de um trabalho interdisciplinar. Sobre a interdisciplinaridade Luck (1994,p.65) ressalta que

A construção do conhecimento interdisciplinar se processa por estágios ou etapas de maturação de consciência. Em vista disso, o esforço de construção do conhecimento interdisciplinar constitui um trabalho de construção da consciência pessoal globalizadora, capaz de compreender complexidades cada vez mais amplas.

É nessa perspectiva apresentada que a interdisciplinaridade e a postura profissional do pedagogo, contribui para o resultado eficaz do trabalho em equipe, ou seja, na perspectiva que o pedagogo partilha seus conhecimentos com outros profissionais isso traz resultados positivos tanto para os profissionais quanto aos sujeitos que receberam o atendimento. Contribuem na reabilitação dos pacientes através de práticas educativas proporcionando aprendizagem, autonomia, independência e enfrentamento da patologia.

RPI Revista de Pesquisa Interdisciplinar, Cajazeiras, v. 1, Ed. Especial, 360 - 369, set/dez. de 2016. 
$\mathrm{Na}$ observação que fizemos foi possível constatar um princípio básico da Educação Especial que é concentrar esforços mais nas habilidades do aluno especial do que em suas limitações. No contexto observado a pedagoga assinala que não foca na patologia do paciente e sim, nas alternativas possíveis de desenvolver o potencial. Investem no que for possível para desenvolver e descobrir o potencial de seus pacientes, empenham-se nessa perspectiva de reabilitar. E explica o que é trabalhar com a vida das pessoas, portanto há uma preocupação com o retorno do sujeito para a casa, a escola e à sociedade. A reabilitação tem o objetivo de tornar o paciente um ser autônomo e independente.

O trabalho do pedagogo hospitalar no Centro de Neurorreabilitação visitado extrapola os muros do hospital. Realizam parte do seu trabalho fora do hospital. Fazem visitas domiciliares, na escola e no trabalho do paciente se for preciso, com o objetivo de conhecer a realidade do paciente e orientar nas adaptações necessárias. As visitas são de acordo com a demanda do paciente, se tiverem dificuldade de adaptações, as pedagogas realizam esse atendimento externo. Já a visita à escola depende da disponibilidade da instituição, pois existe toda uma dinâmica particular. Nesse sentido, é pertinente registrar que um trabalho dessa natureza, onde o pedagogo hospitalar vai até a escola, vai até o trabalho e fornece orientações seguras para a reabilitação do paciente, é realmente um trabalho de excelência que altera para melhor a qualidade de vida do paciente. Para exemplificar esse tipo de atendimento nos relataram acerca de um grupo de adolescentes que estava com dificuldade de socialização, então as pedagogas foram ao FORTAL (Pré-carnaval de Fortaleza) com o grupo de jovens e saiu no bloco chiclete com banana. Relataram que todos se divertiram, ficaram a noite toda e foi maravilhoso. Além desse momento, destacam: passeios à praia, teatro, cinema, shopping, etc., sempre acompanhando os pacientes na perspectiva da reabilitação. É um atendimento hospitalar verdadeiramente humanizado. E as pedagogas são partes integrantes desse processo. Por tudo isso afirmam com satisfação "aqui nós somos reabilitadoras".

Os atendimentos realizados são registrados no prontuário eletrônico. A nosso ver, este é um instrumento valioso para o trabalho interdisciplinar porque, cada profissional tem acesso as informações prestadas pelos profissionais de outras áreas que também atenderam ao paciente.

Acompanhamos o momento em que a pedagoga realizou um atendimento individual com um jovem o qual estava acompanhado de sua mãe, o atendimento aconteceu no espaço da pediatria (espaço limpo, arejado e harmonioso). No primeiro momento, a pedagoga se apresentou para a mãe, e é com ela que começa um questionamento perguntando sobre a

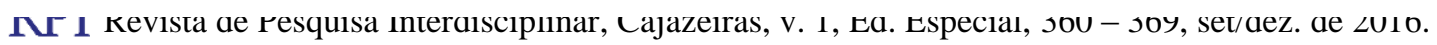


escola na qual o jovem esta matriculado, se é pública ou particular. A mãe afirma que a escola dele e particular, e não paga, porque ela própria é professora da escola. O jovem tem 13 anos de idade e começou a estudar aos 3 anos e faz o $6^{\circ}$ ano. Durante a conversa com a pedagoga, a mãe do jovem relata que o jovem não queria ir mais para a escola porque a professora estava só lendo. Para esse atendimento pedagógico-educacional Fonseca (2008, p.46) enfatiza que

O contato inicial do professor com a criança hospitalar deve, na medida do possível, ocorrer por meio das interações com a mãe, porque, às vezes, a criança fica temerosa com a presença de uma pessoa não famílias, mesmo que não esteja usando um jaleco branco. A mãe servira como mediadora da interação entre a criança e o professor.

De forma clara, objetiva e ética, a pedagoga realiza esse atendimento empoderando a mãe nesse processo, proporcionando apoio e informação. Pergunta à mãe se a escola faz alguma atividade diferenciada para o jovem, e a mãe relata que o professor de educação física de antes fazia sim, mas o atual não faz. E continua relatando que a professora da escola regular passava às vezes produção de texto e às vezes atividades de colagem, e que ela (a mãe) compra todos os livros didáticos, mas o filho só reproduz e não acompanha a turma. A escola não tem adaptação, porém o jovem gosta de participar das festas. A escola o motiva a participar dos eventos.

Atenta às informações que a mãe repassa, a pedagoga pergunta sobre as formas de comunicação do jovem e a mãe diz que ele usa gestos, às vezes fala algumas palavras e escreve no papel, lê os lábios e gosta de usar o facebook para escrever as palavras, quando ele não sabe, utiliza o alfabeto em libras. Percebe-se no relato da mãe que a tecnologia faz parte da comunicação do filho e serve como subsídio para interagir com as pessoas. A partir dessas informações, a pedagoga começa a interagir com o jovem fazendo algumas indagações: Qual o seu melhor amigo? Resposta: Todos. O que você faz na escola? Resposta: Brinco. A mãe relata que ele tem uma boa interação e tem sempre um amigo brincando com ele, porém, ela própria às vezes não entende o que ele fala.

A pedagoga solicitou que o jovem escrevesse o seu nome no papel, depois ela mostrou algumas figuras e perguntou se ele sabia o que era, algumas figuras ele soube responder, outras não. Na tentativa de conhecer a melhor forma de se comunicar com ele, a pedagoga tentou a percepção da fala através de pista tátil para ele entender o que ela perguntava, ele não aceitou essa forma de comunicação, mas escreveu o nome colher no papel. Diante disso a 
pedagoga o elogiou e parabenizou-o. Nesse momento foi possível identificar que realmente cada paciente é tratado como único, e mais, que cada paciente recebe um atendimento pedagógico conforme sua necessidade específica.

O recurso utilizado pela pedagoga está relacionada à tecnologia educacional independente, ou seja, são recursos que dispensam o uso do computador. Para a autora Pocho (2010, p.19) a tecnologia educacional independente

É composta de um conjunto de folhas, geralmente presas em madeira, papelão ou até mesmo em um cabide. Nesse conjunto de folhas, um tema é apresentado com frases curtas, palavras-chaves, ilustrações, gráficos, mapas, histórias ou qualquer outra forma de representação que simbolize as ideias a serem trabalhadas de forma sintética e sequenciada.

Depois disso, a pedagoga combinou com o jovem de acessar no facebook para ver como o jovem utilizava essa ferramenta para se comunicar. Nesse momento o jovem gostou da proposta da pedagoga, antes ele não quis nenhum contato físico com a pedagoga, depois que ela falou que iria utilizar o computador, ele deu um toque de mãos na professora e escreveu na folha a palavra (legal) com um sorriso no rosto. Podemos perceber que o jovem gosta de utilizar o computador e sem dúvida é um recurso que pode ser explorado pelo professor para beneficiar na sua reabilitação. Nesse momento foi possível ver na prática o princípio didático que recomenda ao professor trabalhar com algo que seja do interesse do aluno.

A seguir acompanhamos o trabalho no Grupo de Nutrição na Horta(GNH), essa atividade aconteceu na sala Atividade de Vida Diárias (AVDs). A atividade foi desenvolvida pela pedagoga e pela nutricionista. Os pacientes que participaram faziam parte de um grupo intergeracional composto por crianças, jovens e adultos, todos acompanhados por seus cuidadores.

O objetivo da atividade era orientar aos pacientes sobre uma alimentação mais saudável e motivá-los a incluir nas refeições alimentos naturais e saudáveis que trazem mais benefícios para a saúde. Inicialmente, a pedagoga fez um círculo com todos, explanou o assunto que iria ser abordado naquele momento e depois solicitou que cada um se apresentasse e falasse um pouco de suas vidas. Após o momento de apresentação fez uma explicação sobre produtos naturais e industrializados, mostrando as diferenças e os benéficos para a saúde. A orientação acontece juntamente com a nutricionista, ou seja, percebe-se mais KYI Revista de Pesquisa Interdisciplinar, Cajazeiras, v. 1, Ed. Especial, 360 - 369, set/dez. de 2016. 
uma vez que o trabalho dos profissionais do hospital é realizado intencionalmente de forma interdisciplinar, compartilhando os saberes específicos das diferentes áreas.

Noutro momento atenderam juntos: pedagoga, o professor de educação física e a psicóloga. A atividade realizada foi com aos pacientes da pediatria infantil. Participaram as crianças e seus acompanhantes. A atividade recreativa aconteceu no primeiro andar do hospital, foi o vollençol, utilizando um lençol e uma bola. O objetivo desse jogo é desenvolver o potencial da família. Socialização, interação e orientação familiar. As atividades desenvolvidas pela pedagoga junto com os outros profissionais promoveram experiências lúdicas de socialização e aprendizagem, ao mesmo tempo em que proporcionaram aos pacientes e seus acompanhantes, momentos de diversão e alegria. Sobre o espaço lúdico no hospital, Pinto (2003, p.96) enfatiza que

\begin{abstract}
A hospitalização de uma criança traz consequências psicológicas e a criança começa a apresentar problemas de comportamento, de apetite, de sono e de aprendizagem. Se a criança não puder brincar, durante o período de internação terá seu desenvolvimento comprometido, assim como seu equilíbrio emocional. É brincando que ela vai criar mecanismo de defesa para entender e enfrentar o que está acontecendo.
\end{abstract}

A visita técnica nos permitiu constatar que, quando o hospital proporciona atividades lúdicas para as crianças/jovens, sem dúvida ameniza os danos que a patologia agrega à vida dos pacientes e de seus acompanhantes. E com excelência as pedagogas desempenham essa prática educativa no hospital.

Observamos outra atividade interdisciplinar realizada pela pedagoga, fisioterapeuta e a nutricionista. Foi uma oficina de culinária para pacientes adultos. O local foi a sala de AVDs (Atividades da Vida Diária). Participaram dessa oficina 03 senhoras acompanhadas de suas filhas. A oficina teve como objetivo e resultados: adaptação para cortar, reeducação alimentar, trabalho coletivo e estimular a memória. Numa atividade dessa natureza foi possível constatar que o ato pedagógico verdadeiramente contribui para o desenvolvimento integral do ser humano. A interdisciplinaridade mais uma vez se fez presente no atendimento hospitalar. Saberes, habilidades e competências de profissionais das diferentes áreas interligados na dinâmica do ato de reabilitar.

\title{
Conclusão
}

RPI Revista de Pesquisa Interdisciplinar, Cajazeiras, v. 1, Ed. Especial, 360 - 369, set/dez. de 2016. 
O estudo realizado confirma que a prática educativa exercida pelo pedagogo não se restringe aos muros da escola, vai além deste contexto formal. Foi possível constatar que o pedagogo que atua no âmbito hospitalar, sem dúvida tem uma função relevante no processo de reabilitação dos pacientes que são atendidos pela Unidade Hospitalar que foi locus deste estudo. Ficou evidente que esse novo espaço de atuação, exige do pedagogo qualificação, dedicação, sensibilidade, flexibilidade, competência e ética profissional.

$\mathrm{Na}$ visita técnica realizada na Unidade Hospitalar de Fortaleza-CE constatamos que a formação acadêmica que o pedagogo recebe na universidade, nas disciplinas ofertadas pelo curso de Pedagogia, constitui uma base sólida de conhecimentos teóricos e práticos que o prepara para atuar em múltiplos contextos sociais, incluindo o hospital. Foi possível identificar o pedagogo fazendo uso dos conteúdos de Avaliação, Planejamento, Currículo, Didática, Tecnologias, Artes, Metodologia de Língua Portuguesa, Psicologia, Educação Especial, Educação Infantil, etc. Os referidos conteúdos foram trabalhados no contexto hospitalar.

Dessa forma, os saberes adquiridos e produzidos pelo pedagogo na academia durante o curso de Pedagogia, são compartilhados com outros profissionais da área da saúde. Educação e Saúde se encontram organicamente no processo de inclusão e socialização de crianças/jovens e adultos hospitalizados ou em reabilitação. Portanto, a Pedagogia Hospitalar dá suporte ao indivíduo no seu processo de aprendizagem, garantindo o direito à educação e inclusão.

O estudo veio ratificar que a formação continuada é necessária ao pedagogo nos mais diferentes espaços, sobretudo no âmbito hospitalar por ter suas especificidades. Pois, no contexto em foco são usados conhecimentos oriundos da formação inicial, entretanto as especificidades do contexto hospitalar demandam a formação continuada.

Foi possível observar na prática, a integração entre as diferentes ciências. Este estudo mostrou que os conhecimentos da Pedagogia se somam aos conhecimentos da reabilitação, Neurociência, Psicologia, Medicina, etc., durante o processo de recuperação da saúde do paciente. A equipe é formada por profissionais de diferentes áreas que trabalham de forma integrada, numa abordagem verdadeiramente interdisciplinar. Assim, a vivência da interdisciplinaridade propicia aos profissionais uma interlocução entre os saberes de cada disciplina, ciência ou área de conhecimento.

RPI Revista de Pesquisa Interdisciplinar, Cajazeiras, v. 1, Ed. Especial, 360 - 369, set/dez. de 2016. 
Merece destaque o processo de humanização no serviço oferecido pela Unidade Hospitalar. Os profissionais que ali atuam, entre eles o pedagogo, prestam auxílio e orientação aos familiares dos hospitalizados, no processo de reabilitação. Tal processo dá-se de modo a evidenciar uma postura ética de respeito e diálogo. É princípio do hospital empoderar a família, subsidiando-a com informações que diretamente auxiliem na melhoria da condição de saúde e inserção social do paciente. Neste serviço de orientação a família recebe informações sobre a patologia, os direitos sociais e orientação escolar. Esta orientação constitui-se num atendimento interdisciplinar, o qual é realizado pelo pedagogo juntamente com a equipe hospitalar.

Assim, conclui-se que a Pedagogia é uma ciência com inserção social muito forte na contemporaneidade, posto que pode colaborar para o desenvolvimento humano em diferentes campos sociais. Desse modo, a investigação realizada levou-nos a compreender que o pedagogo está inserido na equipe multidisciplinar do hospital porque, de fato, contribui na reabilitação dos pacientes, ajudando-os a reaprender a viver, apesar de suas limitações, cumprindo eficazmente a filosofia do hospital onde reabilitar é devolver a vida ao paciente.

\section{REFERENCIAS}

FONSECA, Eneida Simões da. Atendimento escolar no ambiente hospitalar.2. ed.São Paulo: Memnon, 2008.

LIBANEO, Jose Carlos. Didática. 28. ed. São Paulo: Editora Cortez, 2008.

LÜCK, Heloísa. Pedagogia interdisciplinar: fundamentos teórico-metodológicos. Petrópolis, Vozes, 1994.

MATOS, Elizete Lúcia Moreira. Pedagogia hospitalar: a humanização integrando educação e saúde.3.ed.Petrópolis, RJ: Vozes, 2008.

PINTO, Marly Rondan. Formação e aprendizagem no espaço lúdico: uma abordagem interdisciplinar. 2.ed. São Paulo: Arte e Ciência, 2003.

POCHO, Claúdia Lopes. Tecnologia educacional: descubra suas possibilidades na sala de aula.5.ed. Petrópolis, RJ: Vozes,2010.

RPI Revista de Pesquisa Interdisciplinar, Cajazeiras, v. 1, Ed. Especial, 360 - 369, set/dez. de 2016. 